JAMP: Jurnal Adminitrasi dan Manajemen Pendidikan

Volume 3 Nomor 2 Juni 2020, Hal : 152-159

Tersedia Online di http://journal2.um.ac.id/index.php/jamp/

ISSN 2615-8574 (online)

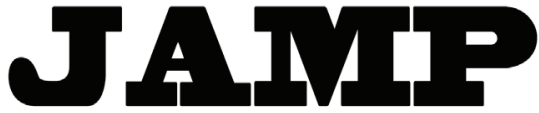

JURNAL ADMINISTRASI DAN MANAJEMEN PENDIDIKAN

\title{
EFEKTIVITAS PROGRAM PEMBERIAN TABLET TAMBAH DARAH UNTUK MENINGKATKAN PERILAKU HIDUP BERSIH DAN SEHAT SISWI SMA NEGERI
}

\author{
Rahmat Hidayat \\ Effendi \\ Alfon Vekoli Laia \\ e-mail: rahmatfitrah85@gmail.com \\ SMA Negeri 4 Tanjung Jabung Barat-Jambi-Indonesia
}

\begin{abstract}
The objective of this study is to describe the effectiveness of iron supplementation program of Merlung Health Center on the enhancement of clean and healthy behaviors (PHBS) of female students in SMA Negeri 4 Tanjung Jabung Barat. This study was a descriptive research carried out for 15 days from the twenty-fifth of September to the eight of October 2019. The subjects were all of female students school year 2019/2020, totaling 200 students. Research data were collected through questionnaire, interview, and documentation. The data were analyzed qualitatively through reduction and display of data, and make conclusions. The results showed that iron supplementation program has succeeded in raising PHBS of female students in SMA Negeri 4 Tanjung Jabung Barat, based on the effectiveness of the program implementation and consciousness of female students to continue to consume iron supplement. The program was effectively implemented based on the number of all of female students consume iron supplementation, with $76 \%$ (152 female students) of whom have compliance to consume iron supplement every week. Furthermore, 155 female students (77.5\%) had the consciousness to continue to consume iron supplement given by Merlung Health Center staff. Iron supplementation program must be continued by involving teachers and parents. Similar research needs to be carried out in other schools in Kecamatan Merlung and Kabupaten Tanjung Jabung Barat, both by school and by health center, in order to obtain data on the effectiveness of the iron supplementation program in schools, so that the implementation of the program can be evaluated and improved.
\end{abstract}

Keywords: effectiveness, iron spplementation program, PHBS

Abstrak: Tujuan penelitian ini ialah untuk mengetahui efektivitas program pemberian tablet tambah darah (TTD) oleh Puskesmas Merlung untuk meningkatkan perilaku hidup bersih dan sehat (PHBS) siswi SMA Negeri 4 Tanjung Jabung Barat. Penelitian ini adalah penelitian deskriptif yang dilakukan selama 15 hari sejak tanggal 25 September 2019 sampai dengan tanggal 8 Oktober 2019. Subjek penelitian adalah seluruh siswi tahun ajaran 2019/2020 yang berjumlah 200 orang. Data penelitian dikumpulkan melalui metode angket, wawancara dan dokumentasi. Data dianalisis secara kualitatif melalui tahapan reduksi data, sajian data dan penarikan kesimpulan. Hasil penelitian menunjukkan bahwa Program pemberian TTD berhasil meningkatkan PHBS siswi SMA Negeri 4 Tanjung Jabung Barat. Hal tersebut didasari atas efektivitas pelaksanaan program dan kesadaran siswi untuk terus mengonsumsi TTD. Efektivitas pelaksanaan program ditunjukkan dengan jumlah seluruh siswi sebanyak 200 orang telah mengonsumsi TTD dengan $76 \%$ (152 siswi) di antaranya patuh untuk selalu mengonsumsi TTD setiap minggu. Selanjutnya, sebanyak 155 siswi $(77,5 \%)$ memiliki kesadaran untuk terus mengonsumsi TTD yang diberikan oleh petugas Puskesmas Merlung. Program pemberian TTD harus terus dilanjutkan dengan melibatkan guru dan orang tua. Penelitian serupa harus pula dilakukan di sekolah-sekolah lain di Kecamatan Merlung dan Kabupaten Tanjung Jabung Barat agar diperoleh data efektivitas program pemberian TTD di lingkungan sekolah, sehingga pelaksanaan program tersebut dapat dievaluasi dan disempurnakan.

Kata kunci: efektivitas, program TTD, PHBS 
Perilaku hidup bersih dan sehat (PHBS) merupakan praktik hidup yang harus dilaksanakan untuk mencapai derajat sehat bagi setiap individu, baik di lingkungan keluarga maupun di lingkungan masyarakat umum. Perilaku tersebut dapat diupayakan dengan dimulai dari penanaman pola pikir sehat kepada masyarakat dan diusahakan oleh diri sendiri (Ardiansyah \& Rahmantari, 2013). Selain itu, dibutuhkan pula komitmen bersama untuk saling mendukung satu sama lain.

Kementerian Kesehatan Republik Indonesia (2011) menjelaskan bahwa PHBS diterapkan pada lima sistem sosial, yaitu rumah tangga, institusi pendidikan, tempat kerja, tempat umum dan fasilitas kesehatan. Salah satu bentuk PHBS di insitusi pendidikan ialah minum tablet tambah darah (TTD) (Kemenkes RI, 2011) yang diberikan oleh puskesmas-puskemas melalui program pemberian TTD. Melalui program pemberian TTD pada remaja putri diharapkan dapat berkontribusi dalam memutus lingkaran malnutrisi antargenerasi (Nuradhiani dkk., 2015), memutus mata rantai terjadinya stunting, mencegah anemia dan meningkatkan cadangan zat besi (Direktorat Gizi Masyarakat, 2016a). Kesadaran mengonsumsi TTD secara berkala dan berkelanjutan menunjukkan bahwa remaja putri telah menerapkan PHBS di lingkungan sekolah.

Tablet tambah darah yang digunakan ialah tablet dengan komposisi terdiri dari $60 \mathrm{mg}$ zat besi elemental (dalam bentuk sediaan Ferro Sulfat, Ferro Fumarat atau Ferro Glukonat) dan 0,400 mg asam folat. Sasarannya ialah remaja putri usia 12 - 18 tahun di institusi pendidikan (SMP dan SMA atau sederajat) dan wanita usia subut usia 15 - 49 tahun di institusi tempat kerja (Direktorat Gizi Masyarakat, 2016a).

Puskesmas Merlung sebagai salah satu fasilitas kesehatan di Kecamatan Merlung yang menjalankan Surat Edaran Nomor HK. 03.03/V/0595/2016 tentang Pemberian TTD pada Remaja Putri dan Wanita Usia Subur melaksanakan program pemberian TTD di seluruh SMP dan SMA di Kecamatan Merlung. Remaja putri usia 12 - 18 tahun yang menjadi sasaran program tersebut akan mudah dijangkau melalui kerjasama dengan SMP dan SMA di Kecamatan Merlung.

SMA Negeri 4 Tanjung Jabung Barat merupakan salah satu SMA di Kecamatan Merlung yang masih berupaya menerapkan PHBS di segala ranah kegiatan sekolah, baik dari sisi siswa maupun dari sisi pendidik dan tenaga kependidikan. Program pemberian TTD di SMA Negeri 4 Tanjung Jabung Barat telah dilaksanakan oleh Puskesmas Merlung sejak tahun 2017 hingga sekarang. Keberlanjutan program tersebut mengindikasikan bahwa TTD telah dikonsumsi oleh siswi SMA Negeri 4 Tanjung Jabung Barat. Namun demikian, belum pernah dilaksanakan evaluasi apakah program tersebut telah efektif dilaksanakan di lingkungan sekolah.

Penulis tertarik untuk meneliti efektivitas program pemberian TTD dan dapatkah program tersebut mendukung PHBS di SMA Negeri 4 Tanjung Jabung Barat. Data efektivitas dan keberhasilan program pemberian TTD penting untuk diperoleh karena akan memberi gambaran akan manfaatnya kepada sekolah serta keunggulan dan kelemahannya untuk menjadi bahan masukan evaluasi program oleh Puskesmas.

Salah satu variabel yang menggambarkan efektivitas program dan penting diperoleh ialah kepatuhan dalam mengonsumsi TTD. Risva dkk (2016) menyatakan bahwa kendala dalam program tersebut ialah kepatuhan. Salah satu meningkatkan kepatuhan konsumsi TTD remaja putri ialah dengan bantuan dari pihak luar, seperti guru (Nuradhiani dkk., 2015). Risva dkk (2016) menyimpulkan penelitiannya bahwa remaja putri lebih patuh mengonsumsi TTD apabila didukung oleh lingkungan yang baik meskipun tingkat pengetahuan tentang anemia masih rendah. Nuradhiani dkk. (2015) dalam salah satu kesimpulan penelitiannya menyatakan bahwa pelaksanaan konsumsi TTD bersama dengan dukungan guru di sekolah dapat membantu remaja putri lebih patuh mengonsumsi TTD.

Penelitian ini bertujuan untuk mengetahui efektivitas program pemberian TTD oleh Puskesmas Merlung dalam meningkatkan PHBS di SMA Negeri 4 Tanjung Jabung Barat. Melalui penelitian ini, diharapkan diperoleh data tentang efektivitas program pemberian TTD sehingga mendukung PHBS di di lingkungan sekolah. Selain itu, bermanfaat pula untuk Puskesmas Merlung sebagai bahan evaluasi dan penyempurna program tersebut. 


\section{METODE}

Penelitian ini adalah penelitian deskriptif kualitatif yang dilaksanakan di SMA Negeri 4 Tanjung Jabung Barat. Penelitian dilaksanakan 15 hari, sejak tanggal 25 September 2019 sampai dengan tanggal 8 Oktober 2019, meliputi persiapan penelitian, pengambilan data, hingga penulisan laporan.

Subjek penelitian ialah seluruh siswi SMA Negeri 4 Tanjung Jabung Barat tahun pelajaran 2019/2020 yang berjumlah 200 orang dari total siswa keseluruhan siswa sebesar 300 orang. Siswi kelas $\mathrm{X}$ tetap dimasukkan ke dalam populasi penelitian. Meskipun mereka baru menjadi peserta didik sejak Bulan Juli 2019, namun mereka telah mendapat TTD di Sekolah Menengah Pertama mereka masingmasing. Penulis mengambil seluruh siswi karena mereka adalah sasaran utama program pemberian TTD di institusi pendidikan. Selain itu, hasil penelitian akan menggambarkan secara utuh efektivitas program pemberian TTD dalam mendukung PHBS di SMA Negeri 4 Tanjung Jabung Barat.

Metode pengumpulan data ialah dengan angket, wawancara, dan dokumentasi. Angket tertutup digunakan untuk mendapatkan data tentang, kepatuhan siswi dalam mengonsumsi TTD, dan persepsi mereka terhadap PHBS dan program pemberian TTD di SMA Negeri 4 Tanjung Jabung Barat. Data persepsi siswi PHBS diperoleh melalui respon mereka atas pertanyaan dengan pilihan jawaban ya, ragu-ragu dan tidak. Data kepatuhan siswi dalam mengonsumsi TTD diperoleh dari pengakuan mereka terhadap intensitas meminum obat TTD setiap diberikan oleh petugas puskesmas. Pengakuan siswa dikategorikan dalam empat tingkatan intensitas dalam meminum TTD, yaitu selalu, sering, jarang, dan tidak pernah, dengan kriteria sebagai berikut.

Tabel 1. Kategori dan kriteria intensitas siswi dalam meminum TTD

\begin{tabular}{ccc}
\hline No & Kategori & Kriteria \\
\hline 1 & Selalu & Siswi meminum TTD 4 kali setiap diberikan oleh petugas puskesmas dalam 1 bulan \\
2 & Sering & Siswi meminum TTD 2 - 3 kali setiap diberikan oleh petugas puskesmas dalam 1 bulan \\
3 & Jarang & Siswi meminum TTD 0 - 1 kali setiap diberikan oleh petugas puskesmas dalam 1 bulan \\
4 & Tidak pernah & Siswi tidak meminum TTD setiap diberikan oleh petugas puskesmas dalam 1 bulan \\
\hline \multicolumn{3}{c}{ Wawancara terstruktur dilakukan kepada petugas Puskesmas Merlung terkait program pemberian } \\
TTD di SMA Negeri 4 Tanjung Jabung Barat. Dokumentasi digunakan untuk mencari data pendukung \\
berupa kehadiran rutin petugas puskesmas lewat buku tamu sekolah.
\end{tabular}

Data yang diperoleh kemudian dianalisis secara kualitatif, melalui tiga tahapan, yaitu: reduksi data, sajian data, dan penarikan kesimpulan. Penulis melakukan penyederhanaan dan transformasi data dari lembar pengamatan dan catatan-catatan pengamat menjadi susunan data yang bermakna untuk selanjutnya dianalisis kemudian ditarik kesimpulan. Verifikasi data dilakukan dengan tiriangulasi sumber data dan diskusi bersama pembimbing. Triangulasi dilakukan untuk melihat konsistensi data dari sumber data, dengan melakukan wawancara kepada 3 orang sampel dengan menanyakaan pertanyaan di dalam angket secara oral. Penulis melakukan wawancara 3 hari setelah data angket diperoleh.

\section{HASIL}

\section{Pelaksanaan Program Pemberian TTD di SMA Negeri 4 Tanjung Jabung Barat}

Program pemberian TTD dilaksanakan oleh Puskesmas Merlung di tingkat SMP dan SMA/SMK di Kecamatan Merlung sejak tahun 2017. Program tersebut pertama kali dilaksanakan di SMA Negeri 4 Tanjung Jabung Barat pada hari rabu tanggal 4 Oktober 2017, dan sejak itu, program pemberian TTD rutin dilaksanakan setiap minggu di SMA Negeri 4 Tanjung Jabung Barat. Program tersebut dilaksanakan setiap hari Kamis, oleh dua orang petugas secara bergantian. Pemberian TTD terus dilakukan hingga penelitian ini dilaksanakan.

Petugas puskesmas memberikan TTD kepada setiap siswi di setiap saat jam pelajaran tengah berlangsung kemudian meminta mereka meminum tablet tersebut saat itu juga atau di waktu jam istirahat. Alasan petugas puskesmas memberikan TTD saat jam pelajaran berlangsung ialah agar tablet tersebut mudah didistribusikan kepada setiap siswi yang hadir serta mudah diawasi oleh guru dalam mengonsumsinya. 

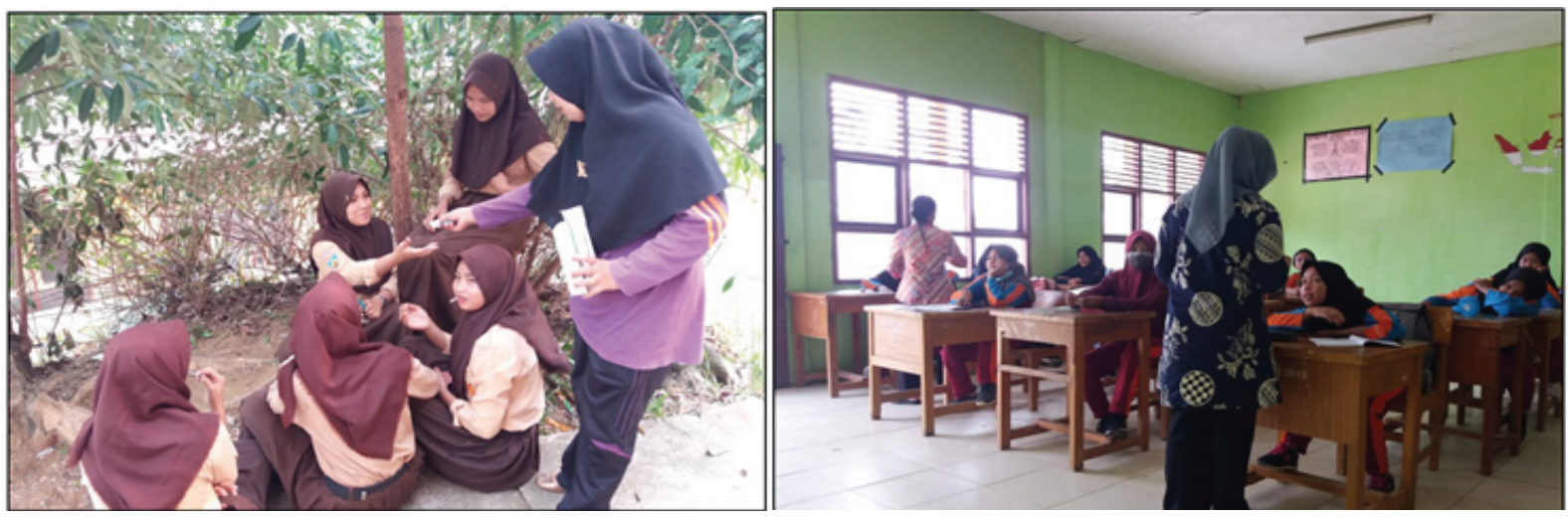

Gambar 1. Aktvitas Petugas Pukesmas memberikan TTD di SMA Negeri 4 Tanjung Jabung Barat

Puskesmas Merlung tidak hanya melaksanakan program pemberian TTD di SMA Negeri 4 Tanjung Jabung Barat, tetapi juga kegiatan-kegiatan lain terkait program PHBS di sekolah. Kegiatan-kegiatan tersebut ialah sosialisasi sekolah yang menerapkan PHBS, pemilihan Duta PHBS SMA Negeri 4 Tanjung Jabung Barat, dan inspeksi jajanan dan kantin yang sesuai PHBS.

\section{Persepsi Siswi SMA Negeri 4 Tanjung Jabung Barat Terhadap Perilaku Mengonsumsi TTD}

Persepsi siswi terhadap perilaku mengonsumsi TTD meliputi pendapat mereka terhadap PHBS dan perilaku mengonsumsi TTD sebelum program pemberian TTD oleh Puskesmas Merlung. Berdasarkan jawaban mereka terhadap angket diketahui bahwa siswi SMA Negeri 4 Tanjung Jabung Barat tidak menerapkan perilaku sehat mengonsumsi TTD. Perhatikan tabel berikut.

Tabel 2. Persepsi Siswi SMA Negeri 4 Tanjung Jabung Barat terhadap Perilaku Mengonsumsi TTD

\begin{tabular}{clccc}
\hline \multirow{2}{*}{ No. } & \multicolumn{1}{c}{ Pertanyaan } & \multicolumn{3}{c}{ Jawaban Siswa } \\
\cline { 2 - 4 } & \multicolumn{1}{c}{ Ya } & Ragu-ragu & Tidak \\
\hline 1 & $\begin{array}{l}\text { Apakah anda setuju bahwa setiap siswa harus berperilaku } \\
\text { hidup bersih dan sehat di sekolah? }\end{array}$ & 200 & - & - \\
2 & $\begin{array}{l}\text { Apakah anda setuju bahwa setiap siswa harus menjaga } \\
\text { kesehatan? }\end{array}$ & 200 & - & - \\
3 & $\begin{array}{l}\text { Apakah anda setuju bahwa kondisi tubuh yang sehat } \\
\text { berdampak baik pada keberhasilan belajar? }\end{array}$ & 200 & - & - \\
4 & $\begin{array}{l}\text { Apakah anda pernah minum tablet tambah darah sebelum } \\
\text { ada program pemberian tablet tambah darah di sekolah? } \\
\text { Apakah anda sering minum tablet tambah darah sebelum } \\
\text { ada program pemberian tablet tambah darah di sekolah? }\end{array}$ & 6 & - & 194 \\
\hline
\end{tabular}

Berdasarkan tabel di atas, seluruh responden (200 orang) menjawab bahwa setiap siswa harus menjaga kesehatan dan berperilaku hidup bersih dan sehat di sekolah. Mereka juga percaya bahwa kondisi tubuh yang sehat akan berdampak baik pada keberhasilan belajar di sekolah. Bertolak belakang dengan persepsi mereka terhadap kesehatan dan PHBS, hanya 6 siswi (3\%) yang pernah meminum TTD, 194 orang lainnya (97\%) tidak pernah minum TTD. Dengan demikian, selain 6 siswi tersebut, tidak ada siswi yang meminum TTD sebelum program pemberian TTD dilaksanakan oleh Puskesmas Merlung.

Berdasarkan data tersebut dapat dijelaskan bahwa siswi SMA Negeri 4 Tanjung Jabung Barat memiliki persepsi yang positif terhadap pentingnya kesehatan dan menjaga kesehatan dalam belajar di sekolah, namun memiliki kesadaran yang rendah terhadap perilaku mengonsumsi TTD. Dengan demikian, seluruh siswi belum menerapkan PHBS di sekolah dalam hal perilaku mengonsumsi TTD.

\section{Kepatuhan Konsumsi TTD oleh Siswi SMA Negeri 4 Tanjung Jabung Barat}

Kepatuhan konsumsi TTD oleh siswi SMA Negeri 4 Tanjung Jabung Barat dinilai dari pengakuan siswa terhadap intensitas meminum obat TTD setiap diberikan oleh petugas puskesmas. Berdasarkan jawaban responden terhadap angket, diperoleh data bahwa semua responden meminum TTD, dengan 
intensitas konsumsi yang berbeda-beda mulai dari selalu, sering, hingga jarang meminum TTD. Namun demikian, sebagian besar siswi selalu meminum TTD setiap kali diberikan oleh petugas puskemas, sebagaimana tergambar pada diagram berikut.

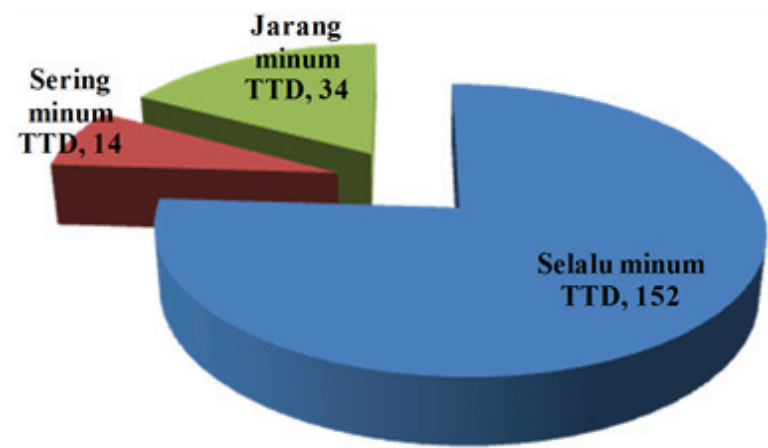

Gambar 2. Diagram kepatuhan konsumsi TTD siswi SMA Negeri 4 Tanjung Jabung Barat

Berdasarkan diagram di atas, kepatuhan siswi SMA Negeri 4 Tanjung Jabung Barat tergolong tinggi yaitu sebesar $76 \%$. Sebanyak 152 siswi patuh terhadap anjuran petugas puskesmas untuk selalu meminum TTD setiap kali diberikan di sekolah. Namun demikian, masih ada 34 siswi (17\%) yang jarang meminum TTD, yang artinya dalam satu bulan mereka hanya minum satu butir TTD atau tidak sama sekali, sehingga mereka paling banyak hanya meminum 12 butir TTD selama 1 tahun. Selanjutnya, 14 siswi (7\%) sering meminum TTD, yang berarti mereka hanya meminum TTD dua sampai tiga kali dalam satu bulan, sehingga mereka paling banyak meminum 36 butir TTD selama 1 tahun.

\section{Persepsi Siswi terhadap Program Pemberian TTD di SMA Negeri 4 Tanjung Jabung Barat}

Persepsi siswi terhadap program pemberian TTD meliputi manfaat yang diperoleh siswi dari program pemberian TTD, konsistensi dalam meminum TTD, dan pendapat mereka tehadap kelangsungan program tersebut. Berdasarkan jawaban responden terhadap angket, diperoleh data bahwa sebagian besar siswi memiliki persepsi yang positif terhadap manfaat dan pentingnya program pemberian TTD di SMA Negeri 4 Tanjung Jabung Barat, sebagaimana tergambar pada tabel berikut.

Tabel 3. Persepsi Siswi SMA Negeri 4 Tanjung Jabung Barat terhadap Program Pemberian TTD

\begin{tabular}{clccc}
\hline \multicolumn{1}{c}{ Pertanyaan } & \multicolumn{1}{c}{$\begin{array}{c}\text { Jawaban Siswa } \\
\text { Ragu-ragu }\end{array}$} & Tidak \\
\hline 1 & $\begin{array}{l}\text { Apakah program pemberian tablet tambah darah } \\
\text { memberi manfaat baik pada anda? }\end{array}$ & 155 & $\mathbf{8}$ & 37 \\
2 & $\begin{array}{l}\text { Apakah anda akan terus mengonsumsi tablet tambah } \\
\text { darah yang diberikan di sekolah? }\end{array}$ & 155 & 6 & 39 \\
3 & $\begin{array}{l}\text { Apakah anda setuju program pemberian tablet tambah } \\
\text { darah terus dilaksanakan? }\end{array}$ & 155 & 6 & 39 \\
\hline
\end{tabular}

Berdasarkan tabel di atas, sebanyak 155 orang dari total 200 siswi (77,5\%) berpendapat bahwa program pemberian TTD memberi manfaat untuk mereka dan akan terus meminum TTD yang diberikan di sekolah. Jumlah responden tersebut tetap konsisten dengan pendapat yang sama bahwa program pemberian TTD harus terus dilaksanakan di SMA Negeri 4 Tanjung Jabung Barat.

Sebanyak 37 orang siswi $(18,5 \%)$ berpendapat bahwa program pemberian TTD tidak memberi manfaat bagi mereka, dan 8 orang siswi (4\%) menjawab ragu-ragu terhadap manfaat program tersebut. Tren angka tersebut berubah ketika diminta pendapat tentang konsistensi mereka dalam meminum TTD pada masa yang akan datang. Sebanyak 2 orang responden dari kelompok siswi yang ragu-ragu terhadap manfaat program pemberian TTD menyatakan tidak ingin melanjutkan meminum TTD. Total jumlah responden yang tidak ingin meminum TTD dan tidak setuju program pemberian TTD dilanjutkan sebanyak 39 orang $(19,5 \%)$.

Persepsi siswa berupa alasan atas kelanjutan program pemberian TTD diperoleh melalui jawaban 
mereka atas angket yang diberikan, yaitu sebanyak 155 siswi yang setuju program dilanjutkan dan sebanyak 39 siswi yang tidak setuju program dilanjutkan. Hasil jawaban mereka sebagaimana tersaji pada diagram berikut.

\section{Setuju Program Pemberian TTD dilanjutkan}

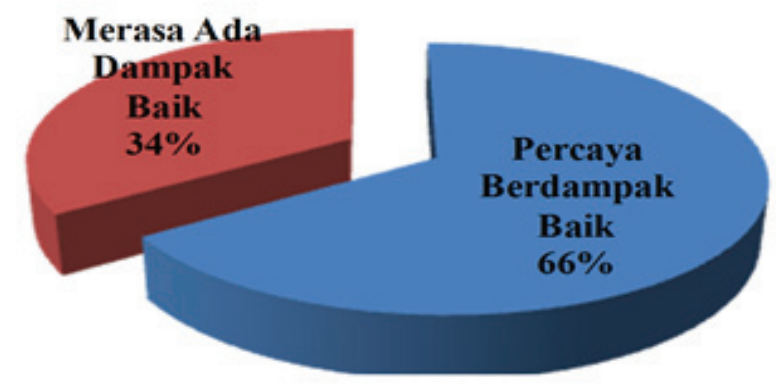

Tidak Setuju Program Pemberian TTD dilanjutkan

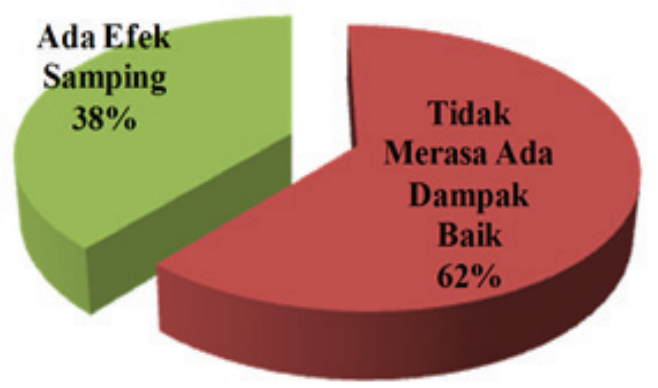

Gambar 3. Diagram alasan setuju dan tidak setuju program pemberian TTD di SMA Negeri 4

Tanjung Jabung Barat terus dilanjutkan.

Dari 155 siswi yang setuju program dilanjutkan, sebanyak 102 siswi (66\%) beralasan bahwa mereka percaya program tersebut berdampak baik bagi kesehatan mereka, sedangkan 53 siswi lain (34\%) merasakan ada dampak baik pada kesehatan tubuh mereka. Selanjutnya, dari 39 siswi yang tidak setuju program dilanjutkan, sebanyak 24 siswi (62\%) beralasan bahwa mereka tidak merasa ada dampak baik pada kesehatan mereka, sedangkan 15 siwi lain (38\%) merasakan bahwa ada efek samping yang muncul dari mengonsumsi TTD, yaitu kepala terasa pusing, mual, bahkan muntah.

\section{PEMBAHASAN}

\section{Efektivitas Program Pemberian TTD di SMA Negeri 4 Tanjung Jabung Barat}

Program pemberian TTD merupakan salah satu program pemerintah untuk memutus mata rantai stunting, mencegah anemia dan meningkatkan cadangan zat besi dalam tubuh, sebagai bekal dalam mempersiapkan generasi yang sehat dan berkualitas dan produktif. Pelaksanaan program di SMA Negeri 4 Tanjung Jabung Barat sejalan dengan tujuan pemerintah tersebut, yang diharapkan berimbas pada peningkatan performa dan dan produktivitas siswi dalam belajar dan melaksanakan tugas yang diberikan oleh guru.

Hasil penelitian menujukkan bahwa program pemberian TTD efektif dilaksanakan di SMA Negeri 4 Tanjung Jabung Barat. Hal tersebut didasari atas dua indikator, pertama, jumlah siswi yang mengonsumsi TTD antara sebelum dan sesudah dilaksanakan program pemberian TTD, dan kedua persentase kepatuhan siswi dalam mengonsumsi TTD. Dua indikator tersebut menggambarkan jumlah minimal konsumsi TTD oleh siswi di SMA Negeri 4 Tanjung Jabung Barat.

Berdasarkan indikator pertama, seluruh siswi SMA Negeri 4 Tanjung Jabung Barat telah mengonsumsi TTD setelah dilaksanakan program pemberian TTD oleh Puskesmas Merlung, meskipun dengan intensitas yang berbeda. Sebelum program dilaksanakan, hanya 3\% (6 siswi) saja yang mengonsumsi TTD. Ada penambahan 194 siswi (97\%) yang mengonsumsi TTD setelah program dilaksanakan. Berdasarkan indikator kedua, jumlah siswi yang selalu mengonsumsi TTD mencapai 152 siswi (76\%). Jumlah TTD yang dikonsumsi siswi dalam 1 kali pemberian oleh Puskesmas Merlung berada pada rentang 152 - 200 butir. Dengan demikian, siswi SMA Negeri 4 Tanjung Jabung Barat paling sedikit mengonsumsi 608 butir dalam 1 bulan atau 7.296 butir selama 1 tahun.

Persentase kepatuhan siswi untuk selalu mengonsumsi TTD hingga 76\% menunjukkan bahwa sebanyak 152 siswi telah mengonsumsi TTD setiap minggu ketika diberikan oleh petugas puskesmas, yang berarti mereka telah menerapkan pola konsumsi TTD ideal sebagaimana anjuran pemerintah melalui Kementerian Kesehatan Republik Indonesia untuk remaja putri dan wanita usia subur dalam 
menanggulangi anemia. Remaja putri dan wanita usia subur idealnya mengonsumsi TTD dengan dosis satu tablet seminggu sekali minimal selama 16 minggu, dan dianjurkan untuk mengonsumsi satu tablet setiap hari selama masa menstruasi (Direktorat Gizi Masyarakat, 2016b).

Capaian persentase tersebut diperoleh dari strategi petugas puskesmas yang memberikan TTD kepada siswi lebih sering di saat jam pelajaran tengah berlangsung dan meminta guru di kelas untuk membujuk dan mengawasi mereka mengonsumsi TTD. Dukungan guru di sekolah yang mengingatkan remaja putri mengonsumsi TTD dapat memberikan sikap positif untuk patuh mengonsumsi TTD (Listiana, 2016).

\section{Upaya Meningkatkan PHBS Siswi melalui Pemberian TTD di SMA Negeri 4 Tanjung Jabung Barat}

Perilaku mengonsumsi TTD merupakan salah satu bentuk PHBS, karena dengan mengonsumsi TTD, kondisi fisik siswi akan bugar, terhindar dari anemia, sehingga tidak rentan terserang penyakit. Dengan kata lain, kesadaran mengonsumsi TTD merupakan pewujudan kesadaran berperilaku hidup bersih dan sehat.

Efektivitas program pemberian TTD menjadi bukti program tersebut dapat meningkatkan PHBS di SMA Negeri 4 Tanjung Jabung Barat. Selain karena efektivitas program, bukti peningkatan PHBS oleh siswi juga didasari atas kesadaran siswi untuk terus mengonsumsi TTD. Sebanyak 155 siswi $(77,5 \%)$ mengaku akan terus mengonsumsi TTD yang akan diberikan oleh Puskesmas Merlung. Mereka juga setuju program pemberian TTD terus dilaksanakan di SMA Negeri 4 Tanjung Jabung Barat. Mereka beralasan bahwa program tersebut memberi dampak baik bagi kesehatan tubuh mereka.

Program pemberian TTD di SMA Negeri 4 Tanjung Jabung Barat dapat lebih ditingkatkan melalui penciptaan lingkungan sekolah yang mendukung program tersebut. Peran serta lingkungan adalah faktor penting dalam meningkatkan kepatuhannya mengonsumsi tablet tambah darah (Risva dkk, 2016). Aktor utama dalam menciptakan lingkungan tersebut ialah wali kelas dan majelis guru agar memberi motivasi kepada seluruh siswi. Puskesmas dan majelis guru duduk bersama meyatukan visi dan menyusun strategi untuk meningkatkan persentase kepatuhan siswa dalam mengonsumsi TTD.

Dukungan guru menjadi faktor yang mempengaruhi tingkat kepatuhan siswi dalam mengonsumsi TTD (Listiana, 2016; Nuradhiani dkk, 2015). Saran-saran yang informatif dan motivatif tentang kebaikan mengonsumsi TTD akan lebih didengar oleh siswa karena guru dan wali kelas yang senantiasa berinteraksi dengan mereka setiap hari. Dukungan guru untuk mengingatkan dalam mengonsumsi TTD serta memberikan informasi mengenai TTD dapat memberikan sikap positif untuk mereka mengonsumsi TTD sesuai anjuran (Listiana, 2016).

Selain dukungan dan informasi, dukungan berupa kontrol guru dalam mengawasi siswa meminum obat juga meningkatkan kepatuhan siswi meningkatkan kepatuhan dalam mengonsumsi TTD. Nuradhiani dkk. (2015) menginformasikan bahwa kontrol guru melalui kartu monitoring kepatuhan dapat pula meningkatkan kepatuhan siswa dalam mengonsumsi TTD. Melalui program kartu monitoring kepatuhan, guru dapat mencatat bahwa remaja putri benar telah mengonsumsi TTD sehingga diperoleh data yang terpercaya sehingga dapat diukur tingkat kepatuhan setiap siswi dalam mengonsumsi TTD.

\section{SIMPULAN DAN SARAN}

\section{Simpulan}

Program pemberian TTD berhasil meningkatkan PHBS siswi SMA Negeri 4 Tanjung Jabung Barat. Hal tersebut didasari atas efektivitas pelaksanaan program dan kesadaran siswi untuk terus mengonsumsi TTD. Efektivitas pelaksanaan program pemberian TTD ditunjukkan dengan jumlah seluruh siswi sebanyak 200 orang telah mengonsumsi TTD dengan 76\% (152 siswi) di antaranya patuh untuk selalu mengonsumsi TTD setiap minggu. Selanjutnya, sebanyak 155 siswi $(77,5 \%)$ memiliki kesadaran untuk terus mengonsumsi TTD yang diberikan oleh petugas Puskesmas Merlung, serta setuju program pemberian TTD terus dilaksanakan di SMA Negeri 4 Tanjung Jabung Barat. 


\section{Saran}

Program pemberian TTD harus terus dilanjutkan dengan melibatkan guru dan orang tua. Puskesmas dan majelis guru bekerjasama menyusun strategi peningkatan konsumsi TTD oleh siswi. Program pemberian kartu monitoring kepatuhan konsumsi TTD laik dicoba, yang ditanda tangani oleh wali kelas dan orang tua sebagai pengawas. Penelitian serupa harus pula dilakukan di sekolah-sekolah lain di Kecamatan Merlung dan Kabupaten Tanjung Jabung Barat, baik oleh pihak sekolah maupun oleh pihak puskesmas, agar diperoleh data efektivitas program pemberian TTD di lingkungan sekolah, sehingga pelaksanaan program tersebut dapat dievaluasi dan disempurnakan.

\section{DAFTAR RUJUKAN}

Andriansyah, Y. \& Rahmantari, D.N. 2013. Penyuluhan dan praktik PHBS (Perilaku Hidup Bersih Sehat) dalam mewujudkan masyarakat desa peduli sehat. Jurnal Inovasi dan Kewirausahaan, 2(1), 45-50.

Direktorat Gizi Masyarakat. 2016a. Surat Edaran Nomor HK. 03.03/V/0595/2016 tentang Pemberian Tablet Tambah Darah pada Remaja Putri dan Wanita Usia Subur. Jakarta: Direktorat Gizi Masyarakat Kementerian Kesehatan Republik Indonesia.

Direktorat Gizi Masyarakat. 2016b. Pedoman pencegahan dan penanggulangan anemia pada remaja putri dan wanita usia subur (WUS). Jakarta: Direktorat Gizi Masyarakat Kementerian Kesehatan Republik Indonesia.

Kemenkes RI. 2011. Peraturan Menteri Kesehatan Republik Indonesia Nomor: 2269/KEMKES/PER/XI/2011 tentang Pedoman Pembinaan Perilaku Hidup Bersih dan Sehat (PHBS). Jakarta: Kementerian Kesehatan Republik Indonesia.

Listiana A. 2016. Analisis faktor-faktor yang berhubungan dengan kejadian anemia gizi besi pada remaja putri di SMKN 1 Terbanggi Besar Lampung Tengah. J Kesehatan, 8(3), 455-469.

Nuradhiani, A., Briawan, D. \& Dwiriani, CM. 2015. Dukungan guru meningkatkan kepatuhan konsumsi tablet tambah darah pada remaja putri di Kota Bogor. Jurnal Gizi Pangan, 12(3), 153-160.

Risva TC, Suyatno \& Rahfiludin, M.Z. 2016. Faktor-faktor yang berhubungan dengan kebiasaan konsumsi tablet tambah darah sebagai upaya pencegahan anemia pada remaja puteri (studi pada mahasiswa tahun pertama di Fakultas Kesehatan Masyarakat Universitas Diponegoro). Jurnal Kesehatan Masyarakat, 4(3), 243-250.

WHO. 2011. Weekly iron and folic acid supplementation programmes for women of reproductive age. An analysis of best programme practices. Geneva: World Health Organization. 